\title{
Evaluation of Regeneration Processes for Filtering Facepiece Respirators in Terms of the Bacteria Inactivation Efficiency and Influences on Filtration Performance
}

\author{
Weidong He, Yinghe Guo, Hanchao Gao, Jingxian Liu, Yang Yue,* and Jing Wang* \\ Cite This: ACS Nano 2020, 14, 13161-13171 \\ Read Online
}

ACCESS I

Llll Metrics \& More

回国 Article Recommendations

Supporting Information

ABSTRACT: The regeneration of filtering facepiece respirators (FFRs) is of critical importance because of the severe shortage of FFRs during large-scale outbreaks of respiratory epidemics, such as COVID-19. Comprehensive experiments regarding FFR regeneration were performed in this study with model bacteria to illustrate the decontamination performance of the regeneration processes. The results showed that it is dangerous to use a contaminated FFR without any microbe inactivation treatment because the bacteria can live for more than $8 \mathrm{~h}$. The filtration efficiency and surface electrostatic potential of $75 \%$ ethanoltreated FFRs were significantly reduced, and a most penetrating particle size of $200 \mathrm{~nm}$ was observed. Steam and microwave irradiation (MWI) showed promising decontamination perform-

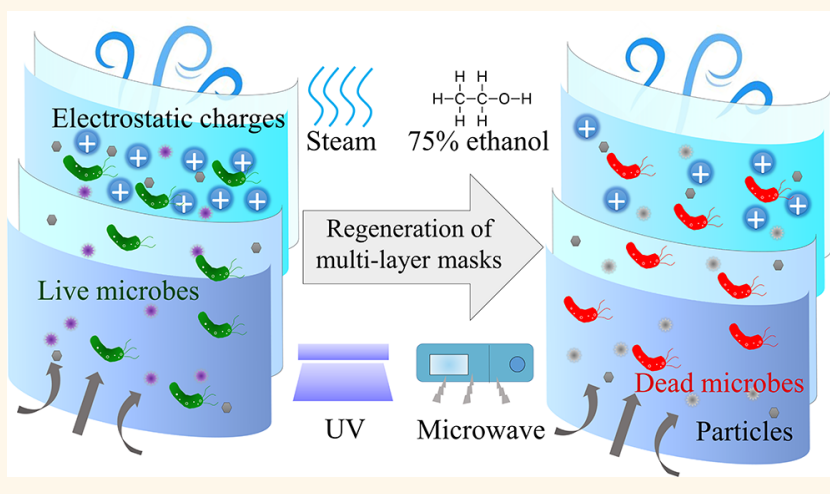
ances, achieving 100\% inactivation in 90 and $30 \mathrm{~min}$, respectively. The filtration efficiencies of steam-treated FFRs for $\mathbf{5 0}$ and $100 \mathrm{~nm}$ particles decreased from $\mathbf{9 8 . 8 6 \%}$ and $\mathbf{9 9 . 5 1 \%}$ to $97.58 \%$ and $\mathbf{9 8 . 7 9 \%}$, respectively. Ultraviolet irradiation (UVI) effectively inactivated the surface bacteria with a short treatment of $5 \mathrm{~min}$ and did not affect the filtration performance. However, the UV dose reaching different layers of the FFP2 mask sample gradually decreased from the outermost layer to the innermost layer, while the model bacteria on the second and third layers could not be killed completely. UVI+MWI and steam were recommended to effectively decontaminate the used respirators and still maintain the respirators' filtration efficiency. The present work provides a comprehensive evaluation for FFR regeneration in terms of the filtration efficiencies for 50-500 nm particles, the electrostatic properties, mechanical properties, and decontamination effects.

KEYWORDS: COVID-19, nanoparticles, mask regeneration, filtration performance, charge decay

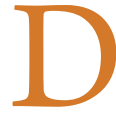

uring the COVID-19 pandemic, many studies have focused on the detection, infection, and transmission of the SARS-CoV-2 virus, ${ }^{1-4}$ as well as personal protection equipment. Filtering facepiece respirators (FFRs) are reliable personal protect equipment that reduce exposure risk to airborne contaminants, such as pathogens, particulate matter, and dust, and are widely used for healthcare in hospitals during seasonal influenza and public health emergencies, e.g., SARS in 2003 and COVID-19 in $2020 .^{4-6}$ Under normal situations, FFRs are produced at a low volume to meet specific requirements, e.g., hospital medical staff and workers with powders/dust/particles. However, during an epidemic or pandemic outbreak, such as COVID-19, FFRs are needed for patients, doctors, and a significant fraction of the general public to protect themselves in order to stop transmission of the pathogen. In such situations, a massive amount of FFRs are required in affected regions over a short period. The World Health Organization (WHO) estimates that 89 million medical masks are required every month and a $40 \%$ increase in manufacturing is required to fill the huge gap between demand and supply during the COVID-19 pandemic. ${ }^{7}$ Mask regeneration and alternative materials for masks have thus attracted strong attention. ${ }^{8,9}$ Historically, the Centers for Disease Control and Prevention (CDC), including

Received: June 8, 2020

Accepted: September 25, 2020

Published: September 25, 2020

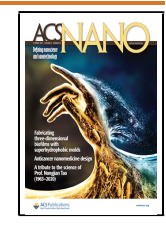




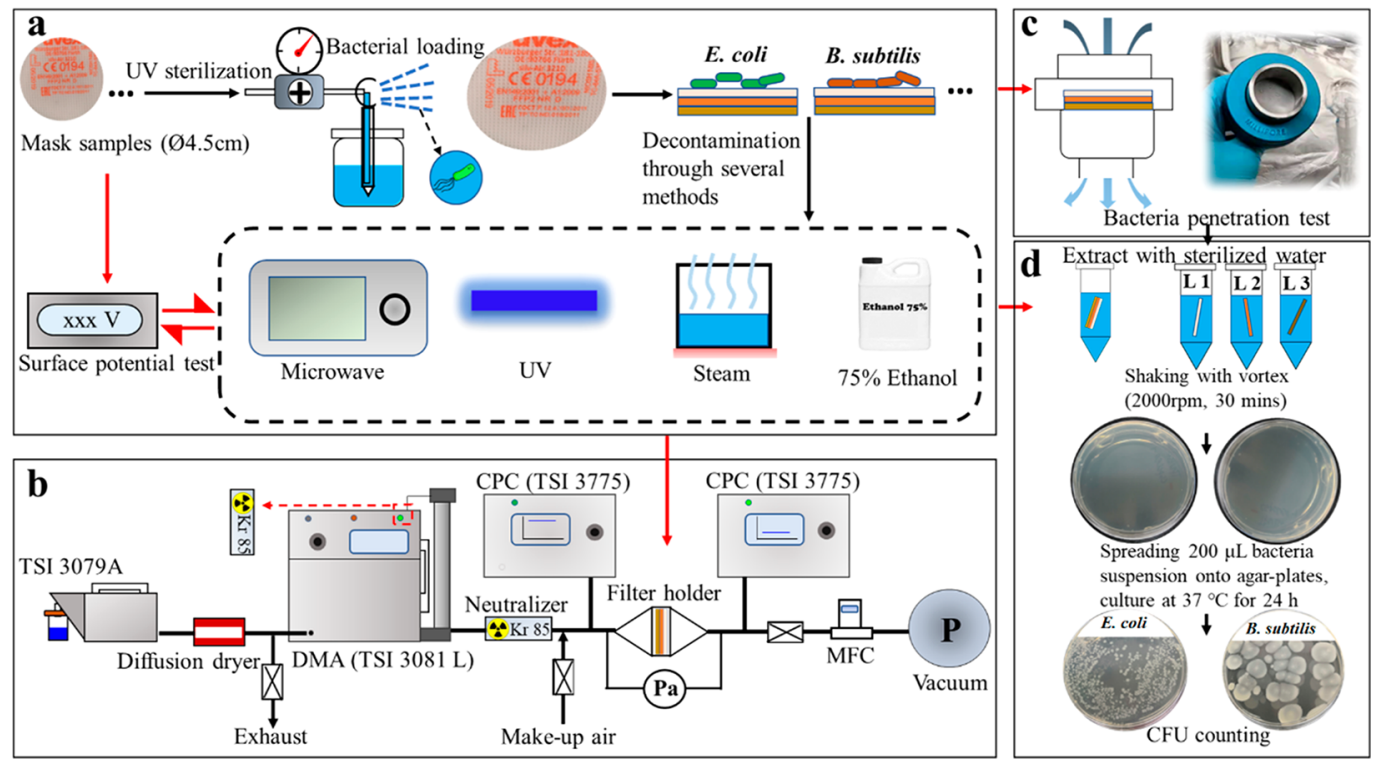

Figure 1. Experimental setup and procedure for FFR regeneration: (a) Bacterial loading and bacteria inactivation treatment. (b) Setup for the particle filtration test. (c) Setup for the bacteria penetration test. (d) Procedure of colony-forming-unit counting. L1, L2, and L3 represent the outermost layer, middle layer, and innermost layer, respectively.

the National Institute for Occupational Safety and Health (NIOSH), issued FFR shortage warnings and developed recommendations for FFRs' reuse during the severe acute respiratory syndrome (SARS 2003) and H1N1 (2009) pandemics. ${ }^{10-12}$ Therefore, although FFRs are designed as disposable products, the regeneration of used FFRs can still be an important option to meet the tremendous shortages during large-scale outbreaks of epidemics transmitted via the airborne route.

The most commonly used N95-equivalent FFRs consist of four layers. ${ }^{13}$ Moving from the outer layer to the inner layers (Figure S1), a hydrophobic outermost layer is used to prevent external moisture; the second layer is a support layer that provides rigidity and designability; the third layer is a meltblown nonwoven polypropylene (PP) layer to capture contaminant particles; and the innermost layer is another hydrophobic layer that minimizes the internal moisture from entering the respirator. The second and third layers stick together and are considered to be the middle layer. The core of an FFR is the middle layer, which provides a particle filtration function through mechanical filtration mechanisms and electrostatic attraction. In order to regenerate used FFRs, proper pathogen inactivation methods should be adopted in order to decrease the infection risk through contact with contaminated FFRs. At the same time, the respirator filtration performance should also be maintained. ${ }^{10}$

During the regeneration process of FFRs, the main concerns are the inactivation of the potential pathogens and maintaining the FFRs' filtration performance. Microbe inactivation methods include physical and chemical techniques. Ethylene oxide (EO), vaporized hydrogen peroxide (HPV), and inorganic hypochlorite are the most commonly applied chemical inactivation methods. In particular, EO is a standard inactivation method for medical devices, ${ }^{14}$ and HPV is approved by the Food and Drug Administration (FDA) to regenerate face masks as a response to the current pandemic. ${ }^{15}$ In principle, the mechanisms of chemical inactivation include reactions with functional proteins, inhibition of enzyme activity, and damage to nucleic acids and membrane transport capacity. ${ }^{16,17}$ Commonly used physical inactivation methods include ultraviolet irradiation (UVI), microwave irradiation (MWI), and steam. The inactivation mechanisms of UVI are damage of the DNA and inhibition of the DNA repair function. ${ }^{18}$ The ability of MWI and steam to inactivate microbes is attributed to thermal effects, which cause protein dysfunction in microbes. ${ }^{19,20}$ So far, UVI, ${ }^{8,15,21-26} \mathrm{MWI}^{21}$ steam, ${ }^{8,24}$ hydrogen peroxide, ${ }^{21,22,27}$ ethylene oxide, ${ }^{21,22}$ $\mathrm{NaOCl}^{21}$ and $\gamma$-rays ${ }^{28}$ have been considered for FFR regeneration. Even though these microbe inactivation methods have been used in various scenarios, their efficacies still need to be evaluated for FFR regeneration, since the microbes may penetrate into the inner layers of the FFR.

The filtration performance of FFRs depends on the physical structure and electrostatic property of the melt-blown layer. For chemical inactivation methods, the corrosion of chemicals may damage the filter's physical structure; ${ }^{29}$ organic solvents such as ethanol may dissipate the charges of electret filters. ${ }^{30}$ In addition, residual chemicals on FFRs may pose adverse health impacts on wearers. ${ }^{21}$ For physical inactivation methods, the mechanical and electrostatic properties of polymer filters may be degraded by the thermal effects of MWI and steam, as well as the aging effect of UVI. ${ }^{30-32}$ Since the COVID-19 outbreak occurred, some general inactivation methods, such as UVI, EO, and hydrogen peroxide, have been proven to have no significant effects on the FFRs' filtration performance and have been recommended for decontaminating FFRs. ${ }^{12,21,22,33}$ Nevertheless, those works were limited by the lack of experiments regarding microbe inactivation. Moreover, the standardized efficiency tests for filter media measure the minimum efficiency at the most penetrating particle size (MPPS). ${ }^{34}$ Measurement at the MPPS is designed to provide information for the worst-case scenario. Many studies have reported that the MPPS of N95-rated FFRs is below 100 nm. ${ }^{35-37}$ A mask used for fighting SARS-CoV-2 should be proven to be efficient in both the size range of respiratory droplets and virus-laden aerosols, which could be suspended in 

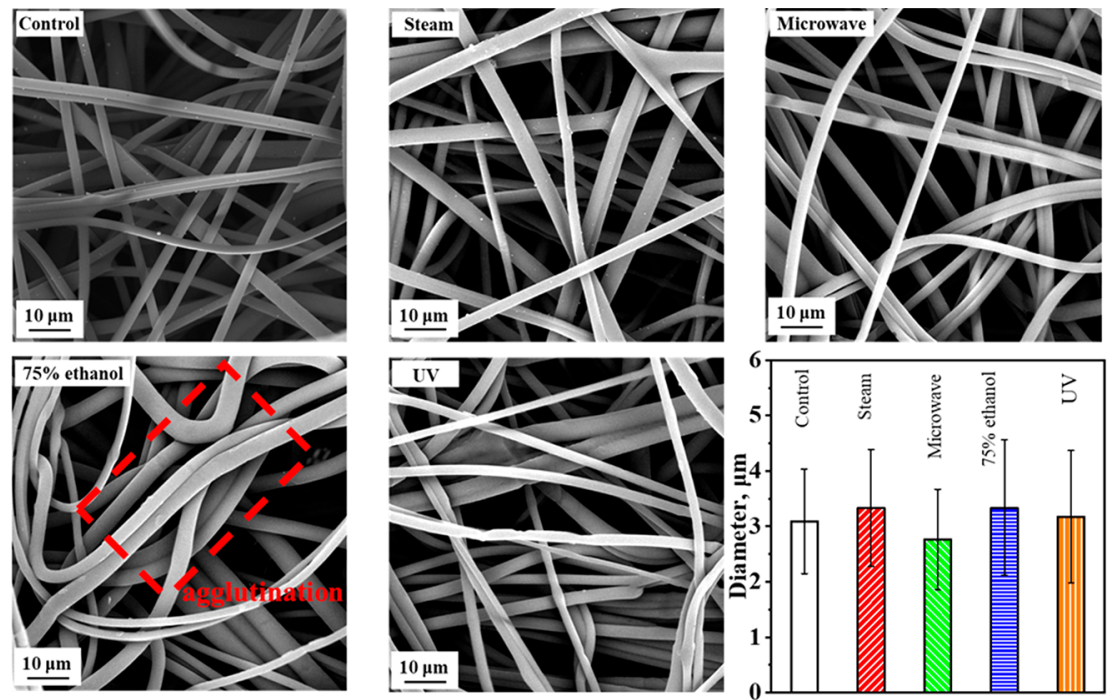

Figure 2. SEM images of the melt-blown layer of regenerated FFP2 circular samples and the average fiber diameter of at least 200 fibers.

the air after the droplets dry out. Measuring the filtration efficiency for micron particles cannot evaluate the minimum efficiency of the regenerated FFRs. Therefore, a particle filtration test for FFRs using nanoscale particles is crucial. In addition, further studies regarding the electrostatic property and pressure drop of regenerated FFRs are urgently needed to support FFR regeneration work.

Model bacteria have been widely used to evaluate the inactivation efficacies of different decontamination methods. For example, under FDA guidelines, the HPV method recently approved for mask regeneration was evaluated by using Geobacillus stearothermophilus spores, ${ }^{38}$ and Escherichia coli and Staphylococcus aureus were used to evaluate the widely used EO method for medical devices. ${ }^{39}$ Suspensions of two commonly used model bacteria (Escherichia coli and Bacillus subtilis), ${ }^{40,41}$ which were used to mimic respiratory droplets containing pathogens, were employed in the present study. The bacteria inactivation efficiencies of MWI, UVI, a combination of UVI and MWI (UVI+MWI), steam exposure, and $75 \%$ ethanol were evaluated. The particle filtration efficiency was measured with particles in the range of 50$500 \mathrm{~nm}$, which covers the size of the SARS-CoV-2 virus and the MPPSs of many commercial FFRs. Moreover, the morphology, pressure drop, and surface potential of the middle layer were measured to assess the filtration performance of regenerated FFRs (Figure 1).

\section{RESULTS AND DISCUSSION}

The filtration performances of newly cut circular mask samples belonging to three categories with different surface potentials were tested (Figure S2 and Table S1). Only FFP2 masks with a high surface potential $(1900 \mathrm{~V})$ demonstrated high filtration efficiencies $(>99 \%)$ for $50-500 \mathrm{~nm}$ particles. The filtration efficiency further increased for particles larger than $500 \mathrm{~nm}$ due to the stronger interception and inertial impaction. Therefore, the N95 masks had even higher efficiencies for respiratory droplets in the micrometer range. The circular surgical mask samples had a filtration efficiency of $>80 \%$ for $50-500 \mathrm{~nm}$ particles and an MPPS of approximately $100 \mathrm{~nm}$. The nonsurgical masks, with a very low surface potential $(50 \mathrm{~V})$, had poor filtration efficiency, and even wearing two of such masks could not provide sufficient protection for the wearers.
The morphology of the melt-blown layer of FFRs may be changed by the thermal effect of steam and microwaves, the aging effect of UV, and the swelling effect of polymer in ethanol. Thus, the morphology of test samples was evaluated in terms of the fibers' diameters and the structure of the meltblown layer before and after regeneration, as shown in Figure 2. The fibers' diameters of FFP2 circular samples regenerated by all bacteria inactivation methods had no statistically significant differences. The melting point of polypropylene is $\sim 160{ }^{\circ} \mathrm{C}$, which is much greater than the temperatures of steam and that generated by short-duration microwave irradiation. Thus, the thermal effect of steam and microwave irradiation had no influence on the fiber's diameter. The effect of UV on the materials strongly depended on the applied dosage. PP was very stable even after UV treatment with $13500 \mathrm{~mJ} / \mathrm{cm}^{2}$, ${ }^{42}$ which was much larger than the maximum applied dosage in this study $\left(378 \mathrm{~mJ} / \mathrm{cm}^{2}\right)$, and no effect on the fiber morphology was observed in the present work. Although it was hard for the ethanol-treated samples to return to their original structure due to the formation of intersegmental bonds with different components, ${ }^{43}$ no change in fiber diameter was observed for the ethanol-regenerated FFP2 circular samples. Compared with the control sample and the samples regenerated by other decontamination methods, the randomly crossed fibers transformed into agglutination after ethanol treatment. Such fiber agglutination might be caused by an increased fiber mobility during the immersion in ethanol, and it was possible that agglutination also affected the pore size.

A drawback of the MWI was that damage occurred when the FFRs were microwaved for a long duration or with a high power output. After the entire FFP2 masks were exposed to $400 \mathrm{~W}$ for more than $10 \mathrm{~min}$ or to $700 \mathrm{~W}$ for $5 \mathrm{~min}$, damage occurred on the nose foam material (Figure S3). This result indicated that the physical inactivation method related to the thermal effect may bring irreversible damage to the filter layer or other components, such as the nose foam material, straps, and nose bridge. In particular, metal materials were adopted as part of the nose bridge by most FFRs brands and should be removed when using the MWI methods. To avoid the damage of FFRs via long-time exposure to microwaves, the duration of a single treatment in our experiments did not exceed $5 \mathrm{~min}$. 


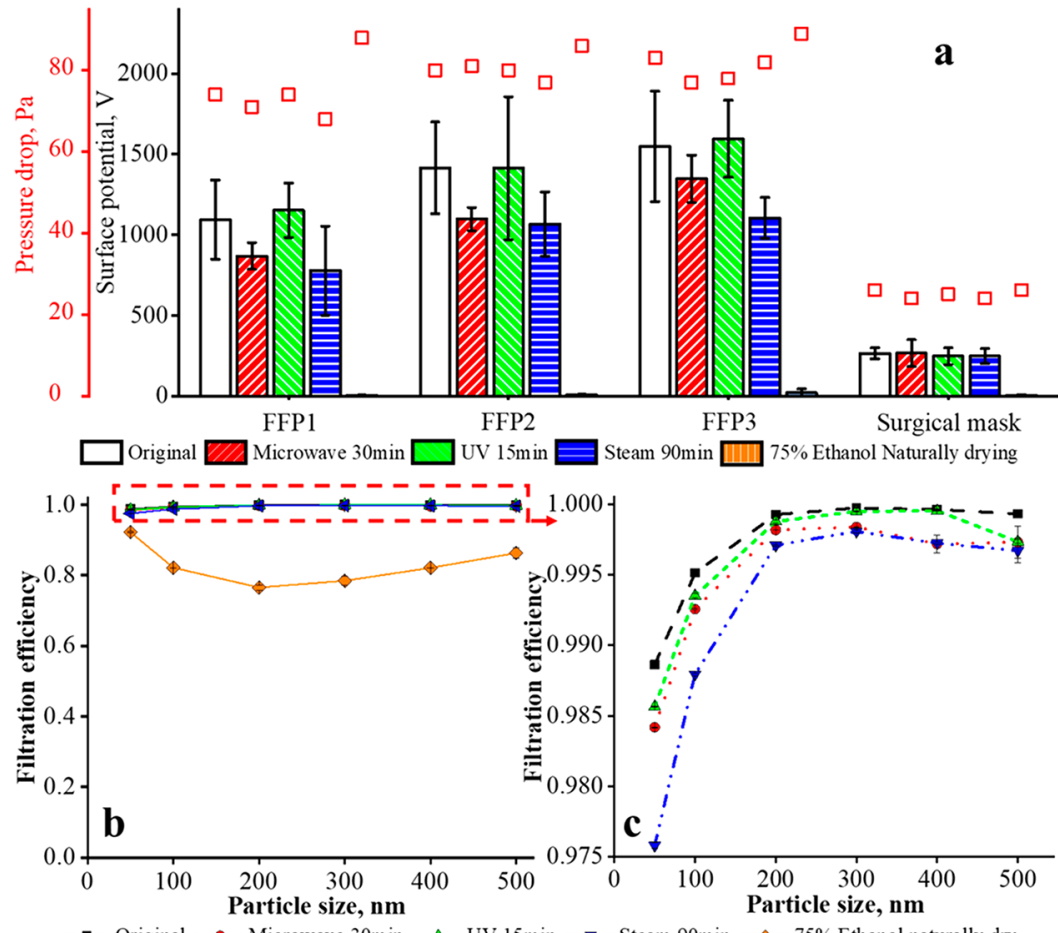

Figure 3. Surface potential, pressure drop, and filtration efficiency of the original and regenerated circular FFR samples: (a) pressure drop at a velocity of $5.3 \mathrm{~cm} / \mathrm{s}$ and the surface potential; (b and c) particle filtration efficiencies of the FFP2 circular samples at a velocity of $5.3 \mathrm{~cm} / \mathrm{s}$.

Thus, MWI inactivation method processing times of $8,10,20$, and $30 \mathrm{~min}$ were the cumulative times for multiple MWI treatment sessions.

For all the regenerated FFP2 circular samples, the porosity had no discernible change compared with the control sample (Table S2). Except for ethanol immersion, all other decontamination methods had no obvious effect on the pressure drop at a velocity of $5.3 \mathrm{~cm} / \mathrm{s}$. The pressure drop of fibrous filters highly depends on the physical structure. As explained before, the fibers' agglutination induced by ethanol immersion was expected to decrease the pore size and resulted in a slight increase in the pressure drop (Figure 3a).

UVI and MWI Had No Influence on the Surface Potential (Figure 3a and Table 1). Both UVI and MWI inactivated the microorganisms based on the radiation effect, which did not directly induce any significant surface charge decay. However, the radiation may indirectly affect the charge decay. UV irradiation can induce a number of oxidized groups, ${ }^{42}$ which made the charges on the polymer surface unstable and easy to transfer. The UV dose used in this work was not sufficient to render the decay of the surface potential. The high temperature accelerated the charge decay of the electret air filter; ${ }^{32}$ thus heat accumulation during longduration MWI may cause degradation of the electrostatic property. In the present study, MWI did not lead to charge decay regardless of the total processing time because of the short-duration irradiation setting.

Ethanol Significantly Induced the Decay of the Surface Potential. Ethanol showed the greatest negative effect on the surface potential among the tested methods (Figure 3a). The surface potential of all circular FFR samples decreased from $265-1545 \mathrm{~V}$ to $\sim 0 \mathrm{~V}$ after ethanol treatment and drying. As an organic solvent, ethanol may lead to the decay of surface potential through several ways, such as charge transfer and charge neutralization. ${ }^{44-46}$ A previous study indicated that charge detrapping was attributed to the swelling of polymer fibers in organic solvents, and the solubility of the polymer filter in different solvents was found to be a ratelimiting factor for charge release. ${ }^{30}$ If chemical decontamination methods are used for FFR regeneration, the solubility between the FFR's materials and the inactivation reagent should be carefully examined.

Steam Inactivation Induced a Slight Decay of the Surface Potential. Previous work reported that high temperature and high humidity could induce a surface charge decay on the electret filters. ${ }^{32}$ Therefore, a significant negative effect of humidity on the surface potential was expected from the steam inactivation method. However, only a slight decrease of the surface potential was measured for all circular FFR samples (Figure 3a). There were several reasons for this unexpected result. In a thermally stimulated discharge (TSD) test, the PP electret filter showed three discharge peaks at 30$50,100-130$, and $165-170{ }^{\circ} \mathrm{C}$, where the discharge intensity increased with an increase in the temperature. ${ }^{47}$ In the present work, the steam exposure was performed under normal atmospheric pressure, and the temperature of the steam in contact with the FFR sample was less than $100{ }^{\circ} \mathrm{C}$. The slight drop in the surface potential may be caused by the detrapping of the interfacial charge at the first discharge peak $\left(30-50^{\circ} \mathrm{C}\right)$. On the other hand, condensed water on hydrophobic layers was observed, which indicated that the outermost layer and innermost layer protected the middle layer. Moreover, the processing time was also an important factor. He et al. showed that the surface potential of a PTFE electret filter dropped less than $50 \%$ of its original value after aging at $100{ }^{\circ} \mathrm{C}$ for $48 \mathrm{~h}^{48}$ Even though the influence of steam inactivation on the surface potential was not significant in this study, attention should be given to the negative effects of high temperature when using 
Table 1. Average Surface Potential (AVG) of Regenerated Circular FFR Samples via the MWI, UVI, and Steam Decontamination Methods and the $p$-Value of the $t$-Test

\begin{tabular}{|c|c|c|c|c|c|c|c|c|c|}
\hline & \multicolumn{3}{|c|}{ MWI } & \multicolumn{3}{|c|}{ UVI } & \multicolumn{3}{|c|}{ steam exposure } \\
\hline & AVG (V) & uncertainty & $p$-value & AVG (V) & uncertainty & $p$-value & AVG (V) & uncertainty & $p$-value \\
\hline FFP 1 & 868.4 & 82.8 & 0.055 & 1152.4 & 168.5 & 0.338 & 777.6 & 276.1 & 0.046 \\
\hline FFP 2 & 1098 & 286.8 & 0.058 & 1413.8 & 443.4 & 0.497 & 1067.4 & 198.9 & 0.029 \\
\hline FFP 3 & 1347.6 & 147.1 & 0.142 & 1595.8 & 238.8 & 0.403 & 1105.2 & 126.9 & 0.021 \\
\hline surgical masks & 265.2 & 83.5 & 0.494 & 247.6 & 51.9 & 0.279 & 247.6 & 46.8 & 0.266 \\
\hline
\end{tabular}
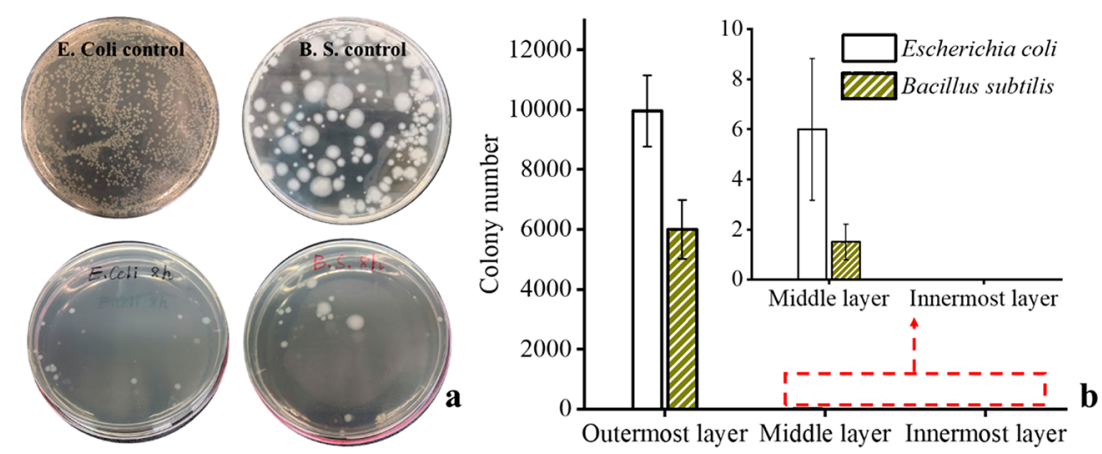

Figure 4. (a) Surviving bacteria under a natural drying situation after $8 \mathrm{~h}$. (b) Distribution of bacteria on different layers of FFP2 masks after a $1 \mathrm{~h}$ penetration test.

autoclaves. As mentioned before, the PP electret filter demonstrated a second discharge peak at $100-130{ }^{\circ} \mathrm{C}$ in the TSD test. The work temperatures of the two basic types of autoclaves (the gravity displacement autoclave and the highspeed prevacuum sterilizer) are in the range of $121-132{ }^{\circ} \mathrm{C}$. ${ }^{49}$ Therefore, a more drastic charge decay of the PP electret filter in autoclaves is likely.

Alteration of Filtration Efficiency at a Velocity of $\mathbf{5 . 3}$ $\mathrm{cm} / \mathrm{s}$ Was Consistent with the Change in the Surface Potential. It is known that N95 masks are one type of electrostatic filter media. ${ }^{35}$ The charge decay of the electrostatic filter media comes with a decreased filtration efficiency and an increased MPPS. ${ }^{50}$ Because of the drastic degradation of the electrostatic property, the filtration efficiencies of ethanol-treated FFP2 circular samples for particles in the range of 50-500 nm decreased significantly (Figure 3b). In addition, an MPPS of $200 \mathrm{~nm}$ for the ethanol-treated FFP2 circular samples was observed. The declined filtration efficiency and shifted MPPS increased the risk of infection when exposed to airborne virus particles. For example, influenza A and SARSCoV-2 have aerodynamic sizes of $80-120 \mathrm{~nm}^{51,52}$ The filtration efficiency of an FFP2 circular sample for $100 \mathrm{~nm}$ particles decreased from $99.51 \%$ to $82.16 \%$ after being decontaminated via ethanol treatment. Compared with the original masks, it would be easier for influenza A and SARS$\mathrm{CoV}-2$ to penetrate the regenerated masks.

For the regenerated FFP2 circular samples via steam decontamination, the filtration efficiencies for 50 and 100 $\mathrm{nm}$ particles decreased from $98.86 \%$ and $99.51 \%$ to $97.58 \%$ and $98.79 \%$, respectively (Figure $3 \mathrm{c}$ ), which was attributed to the slight decrease in the surface potential. According to the analysis results of the Student's $t$-test and one-way ANOVA (analysis of variance) test, the filtration efficiencies of the steam-regenerated FFP2 samples for 50 and $100 \mathrm{~nm}$ particles were statistically significantly different compared with those of the control mask sample (Table S3). The steam decontamination may be suitable for the general public because only slight efficiency decreases for 50 and $100 \mathrm{~nm}$ particles were observed. However, viruses may be resuspended from medical equipment and the floor surface to form virus-laden aerosols, ${ }^{53}$ and aerosol transmission is a possible transmission pathway of COVID-19. ${ }^{54}$ The slight efficiency decrease in steamdecontaminated masks may be of concern for medical staff. The regenerated FFP2 circular samples via UVI and MWI decontamination methods only had a $<0.5 \%$ efficiency drop for $50 \mathrm{~nm}$ particles, which was consistent with the unchanged surface potential.

The surface potential cannot represent the electrostatic charge throughout the entire filter medium. However, the comparison of the surface potential levels of the original and regenerated FFRs provided an indication for the change in the electrostatic property and filtration efficiency. Compared with the aerosol filtration test, the surface potential test requires simpler instruments and offers a faster test procedure. The surface potential test could be used to evaluate regenerated FFRs.

The number of live bacteria decreased with time under natural drying condition (Figure S4). After $8 \mathrm{~h}$, a number of CFUs on the test samples were still observed for both $E$. coli and B. subtilis (Figure 4a), which indicated a high risk for direct reuse of contaminated FFRs without any bacteria inactivation treatment. The aerosolized bacteria were mainly deposited on the outermost layer of the FFP2 circular samples. A few bacteria penetrated into the second layer, but no bacteria were observed on the innermost layer or HEPA filter after the $1 \mathrm{~h}$ penetration test (Figure $4 \mathrm{~b}$ ). The results indicated that the bacteria hardly penetrated to the innermost layer after capture on the masks. The sizes of E. coli and B. subtilis are $0.4-1.5 \mu \mathrm{m}$ in diameter. However, the filtration efficiencies of the outermost layer and the first two layers for airborne 1000 $\mathrm{nm}$ particles were $\sim 13 \%$ and $\sim 57 \%$, respectively (Figure S5), which indicates that more bacteria would deposit on the middle layer of the FFP2 during air filtration processes. The outermost layer of the FFP2 could be considered to be a mechanical fibrous filter with a low filtration efficiency, which was $\sim 36 \%$ for the $120 \mathrm{~nm}$ particles (Figure S5). The sizes of 

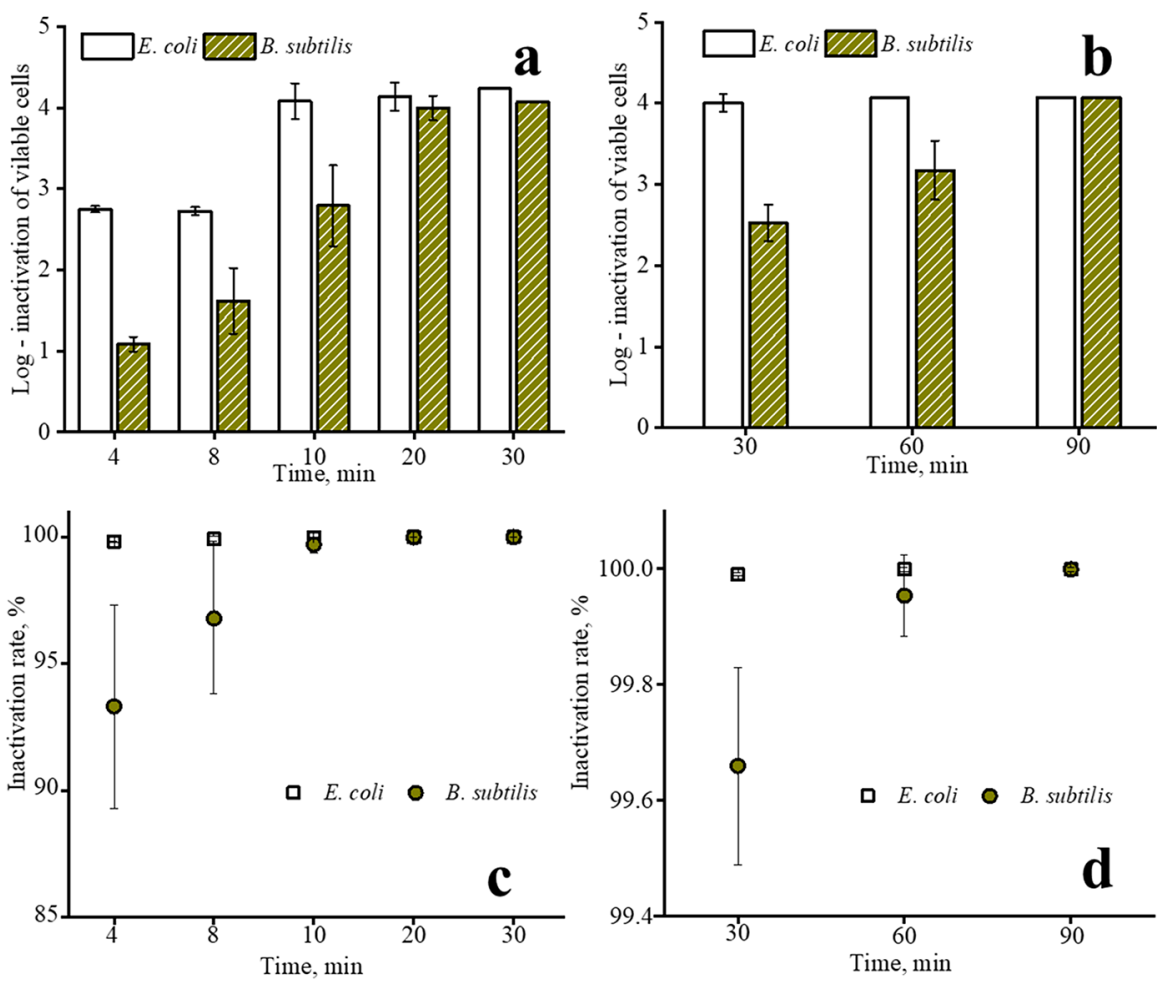

Figure 5. Log reduction and inactivation rate of E. coli and B. subtilis as functions of the processing time using inactivation methods of (a, c) microwave irradiation and $(b, d)$ steam exposure.

coronaviruses are between 80 and $160 \mathrm{~nm} .{ }^{4}$ The sizes of virusladen aerosols can be in a wide range. ${ }^{6,55}$ By applying the precautionary principle in the case of highly dangerous viruses, we consider the possible penetration of virus-laden aerosols through the outermost layer and deposition on the middle layer in the air filtration processes, which may lead to incomplete inactivation by some surface regeneration methods, such as UVI.

UVI Presented a Significant Inactivation Efficacy on $E$. coli and B. subtilis. According to previous studies, the UV dosages required for $\sim 100 \%$ disinfection of various microorganisms were different, i.e., roughly 444 and $120 \mathrm{~mJ} / \mathrm{cm}^{2}$ for E. coli and B. subtilis in water suspensions, respectively. ${ }^{56,57}$ In our experiments, irradiation times of 5, 10, and $15 \mathrm{~min}$ corresponded to 126,252 , and $378 \mathrm{~mJ} / \mathrm{cm}^{2}$ dosages, respectively. No surviving bacterium was observed after UVI treatment for $5 \mathrm{~min}$ or longer (Figure S6a). The UV dosage that achieved $\sim 100 \%$ disinfection of E. coli was lower than the dosage used by Vermeulen et al., ${ }^{56}$ which might be because the UV inactivation method was used for water suspension of bacteria in their work. It is known that part of the UV light is reflected at the water surface. ${ }^{57}$ The filtration performance was maintained even when the UV dosage was increased to 378 $\mathrm{mJ} / \mathrm{cm}^{2}$ (UV for $15 \mathrm{~min}$ ). In fact, the filtration performance of N95 masks was not influenced, even when the UV dosage increased to $20 \mathrm{~J} / \mathrm{cm}^{2},{ }^{23}$ and the UVI could inactivate viruses similar to SARS-CoV-2 on N95 masks when the used dosage was greater than $1 \mathrm{~J} / \mathrm{cm}^{2} .^{24-26}$ Significantly more research is still required to determine the UV dose to inactivate the actual SARS-CoV-2 on the masks in use. A major limitation of UV light is that it can only be used for inactivation on the surface of FFRs. ${ }^{58}$ Due to the poor filtration efficiency of the outermost layer for particles in the range of 50-1000 nm, large fractions of bioaerosol could penetrate to the middle layers during the air filtration processes. Herein, the E. coli and $B$. subtilis suspensions were directly sprayed on the second layer and third layer; then the entire FFP2 circular samples were reassembled and irradiated by UV light for $5 \mathrm{~min}$. The UV dose reaching different layers of the FFP2 mask sample gradually decreased from the outermost layer to the innermost layer (Figure S7a). The E. coli and B. subtilis on the second and third layers of the FFP2 circular samples could not be completely inactivated (Figure S7b).

The results of previous studies ${ }^{24-26}$ together with our data showing penetration into the middle layers by particles with sizes similar to the viruses suggest that the UV dose required to completely inactivate SARS-CoV-2 deposited on the masks should take the mask depth into consideration. The use of UVI alone for FFR regeneration may not disinfect the middle layer of masks, and other auxiliary methods can be adopted to compensate for this deficiency.

Inactivation Efficacy of MWI for E. coli and B. subtilis Depended on the Treatment Time. An inactivation rate of $\sim 100 \%$ (>4 $\log$ reduction) of E. coli and B. subtilis was achieved when the exposure time was extended to 10 and 20 min under a $400 \mathrm{~W}$ output power (Figure 5a and c). In a number of studies on the inactivation of solid materials contaminated by $E$. coli and B. subtilis, the required output powers for the same bacteria reduction were different (Table 2 ). For example, the study by Zhang et al. indicated that a $>4$ $\log$ reduction of $E$. coli deposited on polyacrylonitrile filters was observed when the filters were exposed to $500 \mathrm{~W}$ for $2.5 \mathrm{~min}$. ${ }^{59}$ One of the factors is that the ability of a material to absorb and convert microwave energy to heat was affected by the water content, ${ }^{60}$ and the heat loss increased with an increasing water content. The bacteria-containing water droplets were dried by a diffusion dryer in Zhang et al. ${ }^{59}$ By contrast, the water content of the bacteria aerosol used in the present study was 
Table 2. Summary of the Inactivation of E. coli and B. subtilis by MWI and Steam

\begin{tabular}{|c|c|c|c|c|c|}
\hline research & $\begin{array}{c}\text { inactivation } \\
\text { rate or log } \\
\text { reduction } \\
(\log \text { or } \%)\end{array}$ & $\begin{array}{l}\text { microwave } \\
\text { power or } \\
\text { steam } \\
\text { temperature } \\
\left(\mathrm{W} \text { or }{ }^{\circ} \mathrm{C}\right)\end{array}$ & $\begin{array}{l}\text { time } \\
(\min )\end{array}$ & $\begin{array}{c}\text { model } \\
\text { bacteria }\end{array}$ & $\begin{array}{l}\text { bacteria } \\
\text { loading } \\
\text { media }\end{array}$ \\
\hline \multirow[t]{2}{*}{ ref 59} & $\begin{array}{l}>99.83 \% \\
\quad(>4 \log )\end{array}$ & $500 \mathrm{~W}$ & 2.5 & E. coli & $\begin{array}{l}\text { nanofiber } \\
\text { filter }\end{array}$ \\
\hline & $\begin{array}{l}99.8 \%(2.8 \\
\log )\end{array}$ & $750 \mathrm{~W}$ & 10 & $\begin{array}{l}\text { B. } \\
\text { subtilis }\end{array}$ & $\begin{array}{l}\text { nanofiber } \\
\text { filter }\end{array}$ \\
\hline ref 63 & $\sim 69 \%$ & $700 \mathrm{~W}$ & 1.5 & B. & $\begin{array}{l}\text { airborne } \\
\text { droplets }\end{array}$ \\
\hline \multirow[t]{2}{*}{$\begin{array}{l}\text { present } \\
\text { study }\end{array}$} & $\begin{array}{l}>99.99 \% \\
\quad(>4 \log )\end{array}$ & $400 \mathrm{~W}$ & 10 & E. coli & FFR masks \\
\hline & $\begin{array}{l}>99.99 \% \\
\quad(>4 \log )\end{array}$ & $400 \mathrm{~W}$ & 20 & $\begin{array}{l}\text { B. } \\
\text { subtilis }\end{array}$ & FFR masks \\
\hline \multirow[t]{2}{*}{ ref 64} & $100 \%^{a}$ & $85-90{ }^{\circ} \mathrm{C}$ & 40 & $\begin{array}{l}\text { B. } \\
\text { subtilis }\end{array}$ & $\begin{array}{l}\text { nonwoven } \\
\text { fabric }\end{array}$ \\
\hline & $>99.9 \%$ & $85-90{ }^{\circ} \mathrm{C}$ & 110 & $\begin{array}{l}\text { B. } \\
\text { subtilis }\end{array}$ & $\begin{array}{l}\text { nonwoven } \\
\text { fabric }\end{array}$ \\
\hline \multirow[t]{2}{*}{ ref 65} & $>8 \log ^{b}$ & $111^{\circ} \mathrm{C}$ & 60 & E. coli & $\begin{array}{l}\text { clinical solid } \\
\text { waste }\end{array}$ \\
\hline & $3 \log _{b}-4$ & $111^{\circ} \mathrm{C}$ & 60 & B. ${ }_{\text {subtilis }}$ & $\begin{array}{l}\text { clinical solid } \\
\text { waste }\end{array}$ \\
\hline ref 66 & $2.64 \log ^{c}$ & $100{ }^{\circ} \mathrm{C}$ & 0.5 & E. coli & PVC \\
\hline \multirow[t]{2}{*}{$\begin{array}{r}\text { present } \\
\text { study }\end{array}$} & $\begin{array}{l}>99.99 \% \\
\quad(>4 \log )^{d}\end{array}$ & $90-100{ }^{\circ} \mathrm{C}$ & 30 & E. coli & FFR masks \\
\hline & $\begin{array}{l}>99.99 \% \\
\quad(>4 \log )^{d}\end{array}$ & $90-100{ }^{\circ} \mathrm{C}$ & 90 & B. & FFR masks \\
\hline
\end{tabular}

${ }^{a}$ Assisted by formaldehyde. ${ }^{b}$ With a pressure of 8 psi. ${ }^{c}$ No pressure parameter given. ${ }^{d}$ Atmospheric pressure.

higher; thus the required output power for a $>4$ log reduction of $E$. coli was higher. Another possible factor is that the actual output powers of different microwave oven brands may be different. Moreover, the different properties of air filter materials to reflect and absorb microwaves may cause different levels of heat accumulation, and heat is a major factor determining pathogen inactivation effects. ${ }^{61}$

As mentioned before, a limitation of the MWI inactivation method was that a long-duration continuous operation would damage the FFRs. At the same time, short-duration irradiation indicated an inefficient usage of the total processing time, which prevented it from achieving a high disinfection efficacy and becoming a widely used method. However, the MWI had the advantage of inactivating the bacteria deposited on the middle layer of the FFRs with a thermal effect and specific microwave-induced intracellular changes. ${ }^{62}$ Therefore, shortduration MWI and UVI were likely to be complementary to one another. The UVI and MWI inactivation methods were limited by the penetration depth and operation time, respectively. A potential solution is to use short-duration
MWI to complement the UVI inactivation method. UVI+MWI exhibited excellent inactivation effects. Almost $100 \%$ inactivation of $E$. coli and B. subtilis were observed under different combinations of 5 min UV + 4/8/12 min MWI (Figure S6b). The inactivation method combining UVI and MWI is worth considering in FFR regeneration.

No Surviving Bacteria Were Observed after 75\% Ethanol Treatment (Figure S6c). Ethanol inactivates bacteria by denaturing proteins and dissolving the lipid membrane and is widely used in healthcare settings. ${ }^{67,68}$ Experimental data have shown that alcohol-based inactivation reagents (60\% ethanol, $70 \%$ isopropanol, and alcohol-based hand sanitizers) can inactivate viruses that are genetically related to, and with similar physical properties to, SARS-CoV2. ${ }^{69}$

Sufficient Steam Exposure Time Can Achieve 100\% Inactivation of $E$. coli and $B$. subtilis. For the steam inactivation method, inactivation rates of $\sim 100 \%$ ( $>4$ log reduction) for $E$. coli and $B$. subtilis were observed when the steam exposure times were 30 and $90 \mathrm{~min}$, respectively (Figure $5 \mathrm{~b}$ and $\mathrm{d}$ ). Previous research has reported that $50-85 \%$ relative humidity $(\mathrm{RH})$ enhanced the inactivation rates of microbes. ${ }^{24,70,71}$ The $\mathrm{RH}$ of steam in the present study was $70-85 \%$. Both the thermal effect and high humidity contributed to the bacteria inactivation effects. A number of previous studies regarding the steam inactivation for $E$. coli and B. subtilis are shown in Table 2. Because different heating media and experimental parameters were used, it is not appropriate to compare the results of previous studies directly to the present study. However, the same trend observed in both the present study and previous studies was that $B$. subtilis bacteria were more resistant to steam exposure than $E$. coli. This might be attributed to the thicker cell wall of Grampositive bacteria and the endospore produced by B. subtilis, which provided additional protection against environmental stresses. ${ }^{72}$ According to the latest study, a heating protocol at $92{ }^{\circ} \mathrm{C}$ for $15 \mathrm{~min}$ was effective for SARS-CoV-2 inactivation; ${ }^{73}$ thus the steam inactivation method used in the present study should be valid to similar viruses.

\section{CONCLUSIONS}

As an important piece of personal protect equipment, FFRs have been demanded in gigantic numbers over a short period of time during the COVID-19 pandemic, and severe shortages of FFRs have occurred in most of the COVID-19-infected countries in the past few months. In the present work, we combined filtration tests and a microbial inactivation assessment to evaluate several respirator regeneration methods and to develop detailed protocols in order to achieve the optimal effects of both an efficient microbial decontamination and to

Table 3. Summary of the Treatment Methods for the FFR Samples

\begin{tabular}{|c|c|}
\hline treatment & experimental conditions and parameters \\
\hline microwave & $\begin{array}{l}\text { household microwave oven (Wave 300, Mio Star, Switzerland) with a revolving glass carousel and an output power of } 400 \mathrm{~W} \text {; treatment time: } 4 \text { min } \\
\times 1 \text { cycle, } 4 \text { min } \times 2 \text { cycles, } 5 \text { min } \times 2 \text { cycles, } 5 \text { min } \times 4 \text { cycles, } 5 \text { min } \times 6 \text { cycles; FFR circular samples were placed on a plastic Petri dish; the glass } \\
\text { carousel was cooled to room temperature before the next trial }\end{array}$ \\
\hline UV & $\begin{array}{l}\text { FFR circular samples were treated with UV in a biosafety cabinet with a UV sterilization lamp (BVL } 315 . \mathrm{G} \text {, wavelength } 254 \mathrm{~nm} \text {, Vilber Lourmat, } \\
\text { France); treatment time: } 5 \mathrm{~min}\left(126 \mathrm{~mJ} / \mathrm{cm}^{2}\right), 10 \mathrm{~min}\left(252 \mathrm{~mJ} / \mathrm{cm}^{2}\right) \text {, and } 15 \mathrm{~min}\left(378 \mathrm{~mJ} / \mathrm{cm}^{2}\right)\end{array}$ \\
\hline $\begin{array}{l}\mathrm{UV}+ \\
\text { microwave }\end{array}$ & UV: $5 \mathrm{~min}\left(126 \mathrm{~mJ} / \mathrm{cm}^{2}\right)$; microwave treatment time: $4 \mathrm{~min} \times 1$ cycle, $4 \mathrm{~min} \times 2$ cycles, $4 \mathrm{~min} \times 3$ cycles with an output power of $400 \mathrm{~W}$ \\
\hline steam & $\begin{array}{l}\text { FFR circular samples were steamed for } 30,60 \text {, and } 90 \text { min above boiling water; after the steam treatment, the samples were kept in a biosafety cabinet } \\
\text { and air-dried completely }\end{array}$ \\
\hline & FFR circular samples were immersed in $75 \%$ ethanol for $2 \mathrm{~min}$, then kept in a biosafety cabinet and air-dried completely \\
\hline
\end{tabular}


maintain an acceptable filtration performance. Table 3 summarizes the regeneration protocols in the present study. Ethanol may partially destroy the filter media fibers and surface charge, and it is therefore not suitable for mask regeneration. UVI mainly disinfects the surface bacteria. UVI+MWI may be considered for mask regeneration, but the metal nosepieces should be removed. Steam treatment can efficiently inactivate the bacteria with a slight sacrifice of the surface potential and filtration performance. Therefore, it can also be recommended for mask regeneration.

The filtration efficiency of the regenerated FFP2 masks was tested using 50-1000 $\mathrm{nm}$ particles, which covered the size of the SARS-CoV-2 virus and the MPPSs of many commercial FFRs. The efficiencies of the individual layers of the masks were also measured, which indicated that significant fractions of the airborne submicron particles penetrated into the inner layer of the FFP2. This suggested that the traditional surface decontamination methods might not completely inactivate the deposited pathogens. Furthermore, the surface potential was measured for the original and regenerated FFRs and revealed that the loss of electrostatic charges was the main reason for the decreased filtration efficiency of FFRs treated with ethanol. This result demonstrated that the surface potential measurement could be used to screen the methods for FFR regeneration. Additionally, two model bacteria were used to study the decontamination efficiencies of the FFR regeneration methods. Overall, the current work provided a multifaceted evaluation for FFR regeneration in order to fight COVID-19.

FFRs protect medical staff from job-related risks of exposure to infectious respiratory diseases, and their regeneration is a backup option for healthcare institutions in emergency situations. In any event, the effects of inactivation methods on the physical and filtration properties of FFRs should be carefully evaluated.

\section{MATERIALS AND METHODS}

Materials. Four types of FFRs, including particle filtering face masks (FFP1, FFP2, and FFP3 from UVEX, Switzerland) and surgical face masks (Foliodress, EN 14683 type II), were used in this study. The morphology of the FFRs was characterized via scanning electron microscopy (SEM, Phenom ProX, Eindhoven, The Netherlands). The porosity of the mask samples is defined as $1-\rho / \rho_{0}$, where $\rho$ and $\rho_{0}$ are the bulk density of the porous structures and the density of the solid fibers, respectively. ${ }^{74}$ The value of $\rho$ was obtained by measuring the mass and volume of the circular mask sample, and $\rho_{0}$ was obtained using a Gas Displacement Pycnometry System (Micromeritics, AccuPyc II 1340). All experiments were performed with $4.5 \mathrm{~cm}$ circular discs comprised of the mask material.

Microorganism Preparation. E. coli (K12, a Gram-negative bacteria) and B. subtilis (B 4056, a Gram-positive bacteria), which are widely used as the surrogates of airborne microorganisms, ${ }^{36}$ were purchased from the Culture Collection of Switzerland (CCOS). E. coli and B. subtilis suspensions were prepared with the following procedures. First, the E. coli and B. subtilis were separately inoculated in $50 \mathrm{~mL}$ of liquid Luria-Bertani (LB) broth $(10 \mathrm{~g} / \mathrm{L}$ tryptone, $5 \mathrm{~g} / \mathrm{L}$ yeast extract, and $5 \mathrm{~g} / \mathrm{L}$ sodium chloride). Then the bacteria were cultivated in an incubator at $37^{\circ} \mathrm{C}$ and $50 \% \mathrm{RH}$ for $24 \mathrm{~h}$. Next, the bacteria were separated from the LB liquid broth using a centrifuge. The resulting bacteria were resuspended in sterilized water and centrifuged again. Finally, the bacteria-water suspensions were prepared for a bacteria inactivation test and a penetration test. The obtained bacteria suspensions were shown with a concentration of $\sim 10^{7} \mathrm{CFU} / \mathrm{mL}$, which were analyzed by counting the colony-forming units (CFUs) on an agar plate.

Bacteria Inactivation Methods. All the FFR samples were presterilized via UV radiation in a biosafety cabinet for $20 \mathrm{~min}$.
Bacteria suspensions ( $100 \mu \mathrm{L}, \sim 10^{6}$ cells) in water were aerosolized using a nebulizer and sprayed on each FFR sample (Figure 1a). The bacteria inactivation methods in the present work are summarized in Table 3. As shown in Figure S8, the UV dose reaching different layers of the FFP2 mask sample was measured using a UV intensity meter (model 308, OAI, San Jose, CA, USA).

Filtration Performance Test. The filtration performance was evaluated on cut-out circular pieces of the FFRs with a diameter of 4.5 $\mathrm{cm}$ in a filter holder. The fitting around human faces was not taken into account. In detail, the pressure drop, surface potential, and particle filtration efficiency of the circular FFR samples were tested. All the tests were performed for both original and regenerated circular FFR samples, and triplicate tests of each type FFR were performed. The pressure drop was measured by a pressure transducer (OMEGA PX409-10WDWUUSBH) under a face velocity of $5.3 \mathrm{~cm} / \mathrm{s}$. The circular mask samples were put on a grounded metal platform, and the surface potential was measured using an electrostatic voltmeter (Figure S9). The probe of the electrostatic voltmeter was set at approximately $5 \mathrm{~mm}$ above the test sample. The surface potentials of the five positions on the sample were measured, and the measurement was repeated for three different pieces. During the handling and processing, the charged layer (PP nonwoven layer) was protected by the outermost and supporting layers.

As shown in Figure 1b, the particle filtration test was performed following the same experimental setup described in a previous study. ${ }^{42}$ Briefly, polydisperse $\mathrm{NaCl}$ aerosols were generated by an atomizer (TSI 3079A) and dried by a diffusion dryer. Particles with mobility diameters of 50, 100, 200, 300, 400, and $500 \mathrm{~nm}$ were selected using a differential mobility analyzer (DMA, TSI 3081L) and then neutralized using a $\mathrm{Kr}-85$ source. The particle concentrations upstream and downstream, which were used to calculate the filtration efficiencies of the test samples, were measured by two condensation particle counters (CPC TSI 3775). The particle filtration test was performed only on the FFP2 masks (N95 rated respirators) because they are the most commonly used among the various types of FFRs. The distribution of classified $\mathrm{NaCl}$ particles is shown in Figure S10. The experimental methods of filtration test were in accordance with ISO $21083-1 .^{76}$ According to our previous work, ${ }^{75}$ a sheath to aerosol flow ratio (SAFR) above or equal to 5 in the DMA could be applied in order to minimize the artifact contributed by the multiply charged particles. An SAFR of 10 was used in the present study. Within the velocity range specified by the standards, ${ }^{76,77}$ a face velocity of 5.3 $\mathrm{cm} / \mathrm{s}$ was applied to the FFR samples during the filtration test, because it represented a moderate breathing rate $(55 \mathrm{~L} / \mathrm{min})$ and is a commonly used test velocity for fabric filters and personal protection devices. $^{34}$

Penetration Test of Captured Bacteria. The purpose of the bacteria penetration test was to understand whether or not the captured bacteria could penetrate into the inner layer of the FFR over long-term usage. As shown in Figure 1c, the FFP2 sample was clamped by a filter holder, and a $100 \mu \mathrm{L}$ bacteria suspension $\left(\sim 10^{6}\right.$ cells) in water was sprayed on it. Then the FFP2 sample was tested by a particle-free airflow with a velocity of $5.3 \mathrm{~cm} / \mathrm{s}$ over $1 \mathrm{~h}$, and the penetrated bioaerosol were collected using a high-efficiency particulate air (HEPA) filter. The bacteria on different layers of the FFP2 sample and the HEPA filter were eluted with $10 \mathrm{~mL}$ of sterilized water, and a $200 \mu \mathrm{L}$ eluent was spread on the $\mathrm{LB}$ agar plates $(15 \mathrm{~g} / \mathrm{L}$ agar, $10 \mathrm{~g} / \mathrm{L}$ tryptone, $5 \mathrm{~g} / \mathrm{L}$ yeast extract, and $5 \mathrm{~g} / \mathrm{L}$ sodium chloride, Figure 1d). After cultivation in an incubator at $37^{\circ} \mathrm{C}$ and $50 \% \mathrm{RH}$ for $24 \mathrm{~h}$, the amount of CFU was counted.

Bacteria Inactivation Test of Contaminated Masks. For the bacteria inactivation test, a $100 \mu \mathrm{L}$ bacteria suspension $\left(\sim 10^{6}\right.$ cells $)$ was directly loaded onto the FFP2 circular samples using the nebulizer, and the five methods mentioned before were applied to inactivate the bacteria-contaminated FFP2 circular samples. The regenerated FFP2 and control samples were eluted with 10 and 100 $\mathrm{mL}$ of sterilized water, respectively; then $200 \mu \mathrm{L}$ of eluent was spread on the prepared LB agar plates (Figure 1d). The plates were incubated in an incubator at $37{ }^{\circ} \mathrm{C}$ and $50 \% \mathrm{RH}$ for $24 \mathrm{~h}$, and the 
colonies were counted. The inactivation rate and log reduction of the bacteria were calculated by

$$
\text { Inactivation rate }=\left(1-\frac{N_{1}}{N_{0}}\right) \times 100 \%
$$

$\log$ reduction $=\log N_{0} / N_{1}$

where $N_{1}$ is the CFU number for the bacteria on the regenerated FFR samples and $N_{0}$ is the CFU number for the bacteria on the control sample.

Statistical Analysis. All samples were measured in triplicate, and all data were analyzed using the Origin 2018 software. Student's $t$-test and one-way ANOVA were used for the surface potential, pressure drop, filtration efficiency, and bacteria survival rate results analysis. A $p$-value of less than 0.05 indicated a statistically significant difference at a confidence level of $95 \%$.

\section{ASSOCIATED CONTENT}

\section{(s) Supporting Information}

The Supporting Information is available free of charge at https://pubs.acs.org/doi/10.1021/acsnano.0c04782.

Schematic of the various layers of an FFP2 mask; filtration performance of the samples of nonsurgical masks, surgical masks, FFP2 masks, and the different layers of an FFP2 mask; pictures for bacteria CFU counting; the setup for UV dose and surface potential measurement; size distribution of $\mathrm{NaCl}$ particles for filtration efficiency tests; porosity of regenerated mask samples; raw data used to calculate the filtration efficiency of the steam-regenerated mask sample (PDF)

\section{AUTHOR INFORMATION}

\section{Corresponding Authors}

Yang Yue - Institute of Environmental Engineering, ETH Zürich, Zürich CH-8093, Switzerland; Lab of Advanced Analytical Technologies, Empa, Dübendorf CH-8600, Switzerland; Email: yyue@ethz.ch

Jing Wang - Institute of Environmental Engineering, ETH Zürich, Zürich CH-8093, Switzerland; Lab of Advanced Analytical Technologies, Empa, Dübendorf CH-8600, Switzerland; () orcid.org/0000-0003-2078-137X; Email: jing.wang@ifu.baug.ethz.ch

\section{Authors}

Weidong He - Filter Test Center, Northeastern University, Shenyang, Liaoning CN-110819, China; Institute of Environmental Engineering, ETH Zürich, Zürich CH-8093, Switzerland; Lab of Advanced Analytical Technologies, Empa, Dübendorf CH-8600, Switzerland

Yinghe Guo - Filter Test Center, Northeastern University, Shenyang, Liaoning CN-110819, China; Institute of Environmental Engineering, ETH Zürich, Zürich CH-8093, Switzerland; Lab of Advanced Analytical Technologies, Empa, Dübendorf CH-8600, Switzerland

Hanchao Gao - Institute of Environmental Engineering, ETH Zürich, Zürich CH-8093, Switzerland; Lab of Advanced Analytical Technologies, Empa, Dübendorf CH-8600, Switzerland

Jingxian Liu - Filter Test Center, Northeastern University, Shenyang, Liaoning CN-110819, China

Complete contact information is available at: https://pubs.acs.org/10.1021/acsnano.0c04782

\section{Notes}

The authors declare no competing financial interest.

\section{ACKNOWLEDGMENTS}

The work was partially supported by Innosuisse project 46668.1 IP-ENG "ReMask: Strategies for innovations for Swiss masks needed in pandemic situations" and Center for Filtration Research at University of Minnesota. We thank the support of National Science and Technology Major Project of China (Award IDs: 2017YFC0211801; 2016YFC0801704; 2016YFC0203701; 2016YFC0801605; 2019JH2/10100004). The authors also thank the financial aid from the project of China Scholarship Council, China. We thank Dr. Shanyu Zhao for his help in the porosity measurement.

\section{REFERENCES}

(1) Seo, G.; Lee, G.; Kim, M. J.; Baek, S. H.; Choi, M.; Ku, K. B.; Lee, C. S.; Jun, S.; Park, D.; Kim, S. J.; Lee, J. O.; Kim, B. T.; Park, E. C.; Kim, S. Rapid Detection of COVID-19 Causative Virus (SARSCoV-2) in Human Nasopharyngeal Swab Specimens Using FieldEffect Transistor-Based Biosensor. ACS Nano 2020, 14, 5135-5142.

(2) Qiu, G.; Gai, Z.; Tao, Y.; Schmitt, J.; Kullak-Ublick, G. A.; Wang, J. Dual-Functional Plasmonic Photothermal Biosensors for Highly Accurate Severe Acute Respiratory Syndrome Coronavirus 2 Detection. ACS Nano 2020, 14, 5268-5277.

(3) Kalantar-Zadeh, K.; Ward, S. A.; Kalantar-Zadeh, K.; El-Omar, E. M. Considering the Effects of Microbiome and Diet on SARS-CoV-2 Infection: Nanotechnology Roles. ACS Nano 2020, 14, 5179-5182.

(4) Sahin, A. R.; Erdogan, A.; Agaoglu, P. M.; Dineri, Y.; Cakirci, A. Y.; Senel, M. E.; Okyay, R. A.; Tasdogan, A. M. 2019 Novel Coronavirus (COVID-19) Outbreak: A Review of the Current Literature. EJMO 2020, 4, 1-7.

(5) Martyny, J.; Glazer, C. S.; Newman, L. S. Respiratory Protection. N. Engl. J. Med. 2002, 347, 824-830.

(6) Chen, S. C.; Chio, C. P.; Jou, L. J.; Liao, C. M. Viral Kinetics and Exhaled Droplet Size Affect Indoor Transmission Dynamics of Influenza Infection. Indoor Air 2009, 19, 401.

(7) Zhou, Y. R. The Global Effort to Tackle the Coronavirus Face Mask Shortage. https://theconversation.com/the-global-effort-totackle-the-coronavirus-face-mask-shortage-133656 (accessed 202003-14).

(8) Liao, L.; Xiao, W.; Zhao, M.; Yu, X.; Wang, H.; Wang, Q.; Chu, S.; Cui, Y. Can N95 Respirators Be Reused after Disinfection? How Many Times? ACS Nano 2020, 14, 6348-6356.

(9) Konda, A.; Prakash, A.; Moss, G. A.; Schmoldt, M.; Grant, G. D.; Guha, S. Aerosol Filtration Efficiency of Common Fabrics Used in Respiratory Cloth Masks. ACS Nano 2020, 14, 6339-6347.

(10) Fisher, E. M.; Shaffer, R. E. Considerations for Recommending Extended Use and Limited Reuse of Filtering Facepiece Respirators in Health Care Settings. J. Occup. Environ. Hyg. 2014, 11, 115-128.

(11) National Institute for Occupational Safety and Health (NOISH). Recommended Guidance for Extended Use and Limited Reuse of N95 Filtering Facepiece Respirators in Healthcare Settings. Centers for Disease Control and Prevention (CDC); 2020; https:// w w w. cd c.gov/nios h/topics/h cw controls / recommendedguidanceextuse.html (accessed 2020-09-16).

(12) National Center for Immunization and Respiratory Diseases (NCIRD), Division of Viral Diseases. Implementing Filtering Facepiece Respirator (FFR) Reuse, Including Reuse after Decontamination, When There Are Known Shortages of N95 Respirators. N95 Respirators: Decontamination \& Reuse. Centers for Disease Control and Prevention (CDC); 2020. https://www.cdc.gov/ coronavirus/2019-ncov/hcp/ppe-strategy/decontamination-reuserespirators.html (accessed 2020-09-16).

(13) Zhou, S. S.; Lukula, S.; Chiossone, C.; Nims, R. W.; Suchmann, D. B.; Ijaz, M. K. Assessment of a Respiratory Face Mask for 
Capturing Air Pollutants and Pathogens Including Human Influenza and Rhinoviruses. J. Thorac. Dis. 2018, 10, 2059.

(14) Mendes, G. C.; Brandao, T. R.; Silva, C. L. Ethylene Oxide Sterilization of Medical Devices: A Review. Am. J. Infect. Control 2007, $35,574-581$.

(15) FDA 'OKs' Healthcare Workers to Reuse N95 Face Masks; Here's How They're Being Cleaned. https://wwmt.com/news/local/ fda-oks-healthcare-workers-to-reuse-n95-face-masks-heres-howtheyre-being-cleaned (accessed 2020-03-31).

(16) Fukuzaki, S. Mechanisms of Actions of Sodium Hypochlorite in Cleaning and Disinfection Processes. Biocontrol Sci. 2006, 11, 147157.

(17) Setlow, B.; Loshon, C. A.; Genest, P. C.; Cowan, A. E.; Setlow, C.; Setlow, P. Mechanisms of Killing Spores of Bacillus Subtilis by Acid, Alkali and Ethanol. J. Appl. Microbiol. 2002, 92, 362-375.

(18) Xu, L.; Zhang, C.; Xu, P.; Wang, X. C. Mechanisms of Ultraviolet Disinfection and Chlorination of Escherichia Coli: Culturability, Membrane Permeability, Metabolism, and Genetic Damage. J. Environ. Sci. 2018, 65, 356-366.

(19) Rogers, W. J. Steam and Dry Heat Sterilization of Biomaterials and Medical Devices. In Sterilisation of Biomaterials and Medical Devices; Lerouge, S., Simmons, A.; Woodhead Publishing: Cambridge, 2012; pp 20-55.

(20) Jung, J. H.; Lee, J. E.; Lee, C. H.; Kim, S. S.; Lee, B. U. Treatment of Fungal Bioaerosols by a High-Temperature, Short-Time Process in a Continuous-Flow System. Appl. Environ. Microbiol. 2009, $75,2742-2749$.

(21) Viscusi, D. J.; Bergman, M. S.; Eimer, B. C.; Shaffer, R. E. Evaluation of Five Decontamination Methods for Filtering Facepiece Respirators. Ann. Occup. Hyg. 2009, 53, 815-827.

(22) Viscusi, D. J.; King, W. P.; Shaffer, R. E. Effect of Decontamination on the Filtration Efficiency of Two Filtering Facepiece Respirator Models. J. Int. Soc. Respir. Prot. 2007, 24, 93107.

(23) Martella, M. S.; Ross, A.; Le, C. Research to Mitigate a Shortage of Respiratory Protection Devices During Public Health Emergencies (Report to the FDA No. HHSF223201400158C). Applied Research Associate, Inc. https://www.ara.com/sites/ default/files/MitigateShortageofRespiratoryProtectionDevices_2.pdf (accessed 2020-04-30).

(24) Lore, M. B.; Heimbuch, B. K.; Brown, T. L.; Wander, J. D.; Hinrichs, S. H. Effectiveness of Three Decontamination Treatments against Influenza Virus Applied to Filtering Facepiece Respirators. Ann. Occup. Hyg. 2012, 56, 92-101.

(25) Lowe, J. J.; Paladino, K. D.; Farke, J. D.; Boulter, K.; Cawcutt, K.; Emodi, M.; Gibbs, S.; Hankins, R.; Hinkle, L.; Micheels, T.; Schwedhelm, S.; Vasa, A.; Wadman, M.; Watson, S.; Rupp, M. E. N95 Filtering Facepiece Respirator Ultraviolet Germicidal Irradiation (UVGI) Process for Decontamination and Reuse. https://www. nebraskamed.com/sites/default/files/documents/covid-19/n-95decon-process.pdf (accessed 2020-04-10).

(26) Mills, D.; Harnish, D. A.; Lawrence, C.; Sandoval-Powers, M.; Heimbuch, B. K. Ultraviolet Germicidal Irradiation of InfluenzaContaminated N95 Filtering Facepiece Respirators. Am. J. Infect. Control 2018, 46, e49-e55.

(27) Schwartz, A.; Stiegel, M.; Greeson, N.; Vogel, A.; Thomann, W.; Brown, M.; Sempowski, G. D.; Alderman, T. S.; Condreay, J. P.; Burch, J.; Wolfe, C.; Smith, B.; Lewis, S. Decontamination and Reuse of N95 Respirators with Hydrogen Peroxide Vapor to Address Worldwide Personal Protective Equipment Shortages During the SARS-CoV-2 (COVID-19) Pandemic. Appl. Biosaf. 2020, 25, 67-70.

(28) EU CDC. Cloth Masks and Mask Sterilisation as Options in Case of Shortage of Surgical Masks and Respirators. https://www. ecdc.europa.eu/sites/default/files/documents/Cloth-face-masks-incase-shortage-surgical-masks-respirators2020-03-26.pdf (accessed 2020-03-26).

(29) Schweitzer, P. A. Corrosion of Polymers and Elastomers. Corrosion Engineering Handbook, 2nd Eds.; Taylor and Francis: Boca Raton, 2006; pp 1-16.
(30) Sachinidou, P.; Heuschling, C.; Schaniel, J.; Wang, J. Investigation of Surface Potential Discharge Mechanism and Kinetics in Dielectrics Exposed to Different Organic Solvents. Polymer 2018, 145, 447-453.

(31) Boubakri, A.; Guermazi, N.; Elleuch, K.; Ayedi, H. F. Study of UV-Aging of Thermoplastic Polyurethane Material. Mater. Sci. Eng., A 2010, 527, 1649-1654.

(32) Motyl, E.; Lowkis, B. Effect of Air Humidity on Charge Decay and Lifetime of PP Electret Nonwovens. Fibers Text. East. Eur. 2006, $14,59$.

(33) 3M Steri-Vac Sterilizer/Aerator GS Series. [http://multimedia. $3 \mathrm{~m} . \mathrm{com} / \mathrm{mws} / \mathrm{media} / 1057877 \mathrm{O} / 3 \mathrm{~m}$-steri-vac-ethylene-oxidesterilization-systems.pdf?fn=70-2011-5626-5\%20Steri-Vac\%20Sterili]. $3 \mathrm{M}$ Health Care Infection Prevention Division, St. Paul, MN, USA, 2020.

(34) Wang, J.; Tronville, P. Toward Standardized Test Methods to Determine the Effectiveness of Filtration Media Against Airborne Nanoparticles. J. Nanopart. Res. 2014, 16, 2417.

(35) Martin, S. B.; Moyer, E. S. Electrostatic Respirator Filter Media: Filter Efficiency and Most Penetrating Particle Size Effects. Appl. Occup. Environ. Hyg. 2000, 15, 609-617.

(36) Eninger, R. M.; Honda, T.; Adhikari, A.; Heinonen-Tanski, H.; Reponen, T.; Grinshpun, S. A. Filter Performance of N99 and N95 Facepiece Respirators Against Viruses and Ultrafine Particles. Ann. Occup. Hyg. 2008, 52, 385-396.

(37) Cho, K. J.; Jones, S.; Jones, G.; McKay, R.; Grinshpun, S. A.; Dwivedi, A.; Sgukla, R.; Singh, U.; Reponen, T. Effect of Particle Size on Respiratory Protection Provided by Two Types of N95 Respirators Used in Agricultural Settings. J. Occup. Environ. Hyg. 2010, 7, 622627.

(38) Battelle. Final Report for the Bioquell Hydrogen Peroxide Vapor (HPV) Decontamination for Reuse of N95 Respirators; U.S. Food and Drug Administration, 2016.

(39) Rutala, W. A.; Gergen, M. F.; Sickbert-Bennett, E. E.; Weber, D. J. Comparative Evaluation of the Microbicidal Activity of LowTemperature Sterilization Technologies to Steam Sterilization. Infect. Control Hosp. Epidemiol. 2020, 41, 391-395.

(40) Yu, K. P.; Lee, G. W. M.; Lin, S. Y.; Huang, C. P. Removal of Bioaerosols by the Combination of a Photocatalytic Filter and Negative Air Ions. J. Aerosol Sci. 2008, 39, 377-392.

(41) Montville, T. J.; Dengrove, R.; De Siano, T.; Bonnet, M.; Schaffner, D. W. (2005). Thermal Resistance of Spores from Virulent Strains of Bacillus Anthracis and Potential Surrogates. J. Food Prot. 2005, 68, 2362-2366.

(42) Hill, J. M.; Karbashewski, E.; Lin, A.; Strobel, M.; Walzak, M. J. Effects of Aging and Washing on UV and Ozone-Treated Poly (ethylene Terephthalate) and Polypropylene. J. Adhes. Sci. Technol. 1995, 9, 1575-1591.

(43) Wang, P. P.; Lee, S.; Harmon, J. P. Ethanol-Induced Crack Healing in Poly (methyl Methacrylate). J. Polym. Sci., Part B: Polym. Phys. 1994, 32, 1217-1227.

(44) Cantaloube, B.; Dreyfus, G.; Lewiner, J. Vapor-Induced Depolarization Currents in Electrets. J. Polym. Sci., Polym. Phys. Ed. 1979, 17, 95-101.

(45) Ohmi, T.; Sudoh, S.; Mishima, H. Static Charge Removal with IPA Solution. IEEE T. Semiconduct. M. 1994, 7, 440-446.

(46) Xiao, H.; Song, Y.; Chen, G. Correlation between Charge Decay and Solvent Effect for Melt-Blown Polypropylene Electret Filter Fabrics. J. Electrost. 2014, 72, 311-314.

(47) Kilic, A.; Russell, S.; Shim, E.; Pourdeyhimi, B. The Charging and Stability of Electret Filters. In Fibrous Filter Media; Brown, P. J.; Cox, C. L.; Woodhead Publishing, 2017; pp 95-121.

(48) He, W.; Zhao, Y. B.; Jiang, F.; Guo, Y.; Gao, H.; Liu, J.; Wang, J. Filtration Performance and Charge Degradation During Particle Loading and Reusability of Charged PTFE Needle Felt Filters. Sep. Purif. Technol. 2020, 233, 116003.

(49) CDC. Steam Sterilization. https://www.cdc.gov/ infectioncontrol/guidelines/disinfection/sterilization/steam.html (accessed 2020-04-26). 
(50) Choi, H.-J.; Kim, S.-B.; Kim, S. H.; Lee, M.-H. Preparation of Electrospun Polyurethane Filter Media and Their Collection Mechanisms for Ultrafine Particles. J. Air Waste Manage. Assoc. 2014, 64, 322-329.

(51) Bionumbers. How Big are Viruses? http://book.bionumbers. org/how-big-are-viruses/ (accessed 2020-04-29).

(52) Encyclopaedia Britannica. Coronavirus. https://www. britannica.com/science/coronavirus-virus-group (accessed 2020-0420).

(53) Liu, Y.; Ning, Z.; Chen, Y.; Guo, M.; Liu, Y.; Gal, N. K.; Sun, L.; Duan, Y.; Cai, J.; Westerdahl, D.; Liu, X.; Xu, K.; Ho, K.; Kan, H.; $\mathrm{Fu}, \mathrm{Q}$.; Lan, K. Aerodynamic Analysis of SARS-CoV-2 in Two Wuhan Hospitals. Nature 2020, 582, 557-560.

(54) WHO. Transmission of SARS-CoV-2: Implications for Infection Prevention Precautions (WHO Scientific Brief, July 9, 2020), WHO/2019-nCoV/Sci_Brief/Transmission_modes/2020.3. WHO, 2020.

(55) Hinds, W. C. Bioaerosol. In Aerosol Technology: Properties, Behavior, and Measurement of Airborne Particles, 2nd ed.; John Wiley \& Sons: Los Angeles, 1999; pp 394-396.

(56) Vermeulen, N.; Keeler, W. J.; Nandakumar, K.; Leung, K. T. The Bactericidal Effect of Ultraviolet and Visible Light on Escherichia Coli. Biotechnol. Bioeng. 2008, 99, 550-556.

(57) Qualls, R. G.; Johnson, J. D. Bioassay and Dose Measurement in UV Disinfection. Appl. Environ. Microbiol. 1983, 45, 872-877.

(58) Weber, D. J.; Rutala, W. A. Self-Disinfecting Surfaces. Infect. Control Hosp. Epidemiol. 2012, 33, 10-13.

(59) Zhang, Q.; Damit, B.; Welch, J.; Park, H.; Wu, C. Y.; Sigmund, W. Microwave Assisted Nanofibrous Air Filtration for Disinfection of Bioaerosols. J. Aerosol Sci. 2010, 41, 880-888.

(60) Chandrasekaran, S.; Ramanathan, S.; Basak, T. Microwave Food Processing-A Review. Food Res. Int. 2013, 52, 243-261.

(61) Bertrand, I.; Schijven, J. F.; Sánchez, G.; Wyn-Jones, P.; Ottoson, J.; Morin, T.; Muscillo, M.; Verani, M.; Nasser, A.; de RodaHusman, A. M.; Myrmel, M.; Sellwood, J.; Cook, N.; Gantzer, C. The Impact of Temperature on the Inactivation of Enteric Viruses in Food and Water: A Review. J. Appl. Microbiol. 2012, 112, 1059-1074.

(62) Goldblith, S. A.; Wang, D. I. Effect of Microwaves on Escherichia coli and Bacillus subtilis. Appl. Microbiol. 1967, 15, 13711375

(63) Wu, Y.; Yao, M. Inactivation of Bacteria and Fungus Aerosols Using Microwave Irradiation. J. Aerosol Sci. 2010, 41, 682-693.

(64) Alder, V. G.; Brown, A. M.; Gillespie, W. A. Disinfection of Heat-Sensitive Material by Low-Temperature Steam and Formaldehyde. J. Clin. Pathol. 1966, 19, 83-89.

(65) Hossain, M.; Balakrishnan, V.; Rahman, N. N. N. A.; Sarker, M.; Islam, Z.; Kadir, M. O. A. Treatment of Clinical Solid Waste Using a Steam Autoclave as a Possible Alternative Technology to Incineration. Int. J. Environ. Res. Public Health 2012, 9, 855-867.

(66) Ban, G. H.; Yoon, H.; Kang, D. H. A Comparison of Saturated Steam and Superheated Steam for Inactivation of Escherichia coli O157: H7, Salmonella typhimurium, and Listeria monocytogenes Biofilms on Polyvinyl Chloride and Stainless Steel. Food Control 2014, 40, 344-350.

(67) Kampf, G. Efficacy of Ethanol Against Viruses in Hand Disinfection. J. Hosp. Infect. 2018, 98, 331-338.

(68) Kampf, G.; Ostermeyer, C.; Werner, H. P.; Suchomel, M. Efficacy of Hand Rubs with a Low Alcohol Concentration Listed as Effective by a National Hospital Hygiene Society in Europe. Antimicrob. Resist. Infect. Control 2013, 2, 19.

(69) CDC. Hand Hygiene Recommendations. https://www.cdc. gov/coronavirus/2019-ncov/hcp/hand-hygiene.html (accessed 202005-17).

(70) Bergman, M. S.; Viscusi, D. J.; Heimbuch, B. K.; Wander, J. D.; Sambol, A. R.; Shaffer, R. E. Evaluation of Multiple (3-Cycle) Decontamination Processing for Filtering Facepiece Respirators. J. Eng. Fibers Fabr. 2010, 5, 33-41.

(71) McDevitt, J.; Rudnick, S.; First, M.; Spengler, J. Role of Absolute Humidity in the Inactivation of Influenza Viruses on
Stainless Steel Surfaces at Elevated Temperatures. Appl. Environ. Microbiol. 2010, 76, 3943-3947.

(72) Mai-Prochnow, A.; Clauson, M.; Hong, J.; Murphy, A. B. Gram Positive and Gram Negative Bacteria Differ in Their Sensitivity to Cold Plasma. Sci. Rep. 2016, 6, 38610.

(73) Pastorino, B.; Touret, F.; Gilles, M.; de Lamballerie, X.; Charrel, R. N. Heat Inactivation of Different Types of SARS-CoV-2 Samples: What Protocols for Biosafety, Molecular Detection and Serological Diagnostics? Viruses 2020, 12, 735.

(74) Zeng, Z.; Wu, T.; Han, D.; Ren, Q.; Siqueira, G.; Nyström, G. Ultralight, Flexible, and Biomimetic Nanocellulose/Silver Nanowire Aerogels for Electromagnetic Interference Shielding. ACS Nano 2020, 14, 2927-2938.

(75) Sachinidou, P.; Bahk, Y. K.; Wang, J. An Integrative Model for the Filtration Efficiencies in Realistic Tests with Consideration of the Filtration Velocity Profile and Challenging Particle Size Distribution. Aerosol Sci. Technol. 2017, 51, 178-187.

(76) International Organization for Standardization (ISO), ISO 21083-1: Test Method to Measure the Efficiency of Air Filtration Media Against Spherical Nanomaterials-Part 1: Size Range from 20 to $500 \mathrm{~nm}$; Switzerland, 2018.

(77) American Society for Testing and Materials (ASTM), ASTM F2100-19e1: Standard Specification for Performance of Materials Used in Medical Face Masks; ASTM International: West Conshohocken, 2019. 